\section{THE SCIENCE SECTION OF THE TURIN INTERNATIONAL EXHIBITION.}

$W$ HEN the scope of the Franco-British Exhibition was under consideration, the British Science Guild approached the organisers and suggested that a science section should be arranged. The suggestion was agreed to; and it will be remembered how successful the exhibit was, and what a large amount of interest it aroused. Since then similar exhibits have been arranged at the Japan-British Exhibition and the present Coronation Exhibition, and still continue to attract attention.

The Exhibitions Branch of the Board of Trade has, at the instance of the Physical Instruments and the Chemical Committees of the Royal Commission appointed to deal with the exhibitions at Brussels, Rome, and Turin, organised an exhibit on somewhat similar lines. It was realised that at international and other exhibitions physical and chemical instruments and apparatus are not shown to advantage. The facilities for examination of the instruments are inadequate, owing to the fact that they are usually shut up in cases. Generally speaking, also, there is no one there to take them out and explain them to those who may be interested. It was therefore decided to instal working chemical and physical laboratories, in which exhibitors would have, for the first time in international exhibitions, an opportunity of having their instruments explained and demonstrated. The educational value of such a system of exhibiting is obvious, not only from the point of view of the manufacturers, but also to the public. The average person has no idea of what goes on in a pliysical or chemical laboratory, or what the apparatus, generally seen in a case, is employed for. In these laboratories actual experimental work can be seen in operation, and the demonstrators are there to give explanations to those seeking information. It should be mentioned here that professors and students from the universities and polytechnics on the Continent have taken great interest in the laboratories, in many cases spending several hours, and coming not once, but several times.

A Joint Committee of Mathematical and Scientific Instruments and Chemical Industries Committees was appointed to deal with the matter and to appoint competent scientific representatives to act as demonstrators in the laboratories.

The laboratory fittings were constructed by Messrs. Baird and Tatlock, Ltd., under the directions of the joint committee and personal supervision of Dr. F. Mollwo Perkin.

In the physical laboratory a dark-room has been set apart, where demonstrations are given with the well-known optical lantern of Messrs. Reynolds and Branson. The lantern employed is a special one fitted with a movable stage, so that it can be used for ordinary optical work and for illustrating practical experiments in science teaching. It is also fitted with a polariser, which, by moving the stage, can be brought into position, and by a further movement of the stage a microscope of special design can be used. Thus bacteriological, physiological, and naturalhistory specimens can be shown.

On the bench adjoining the dark-room Messrs. Reynolds and Branson exhibit other types of lanterns, and the Barr and Stroud lantern-slide apparatus. This very convenient piece of apparatus is fitted with graduated scales, which enable the operator without calculations or focussing on the screen, rapidly to prepare a lantern-slide.

Beyond this is an interesting exhibit by Robert Paul of electrical apparatus, including the Irwin oscillograph, on which are shown both the current and pressure curves of the alternating current, supplied by a small alternator of the Crypto Electrical Company, and complete apparatus for making measurements of self-induction by means of the Campbell variable mutual inductance, the alternating current being obtained by a microphone hummer.

On the next bench Messrs. J. J. Griffin and Sons show Sand's apparatus for the electro-deposition of metals, and their separation by means of an auxiliary electrode, the potentiometer box containing a capillary electrometer of special design. On the opposite bench Messrs. Townson and Mercer exhibit apparatus for the demonstration of the laws of mechanics, and also certain laboratory electrical instruments.

Messrs. Adam Hilger show their wave-length spectroscope. Other apparatus on this bench consists of a collection of electrical and magnetic testing instruments by Messrs. Baird and Tatlock, Negretti and Zambra, the well-known " Tintometer" for colour estimation, two mathematical models in plaster by Prof. Crum Brown, F.R.S., and a "Geryk" vacuum pump by the Pulsometer Engineering Co., Ltd.

On a separate bench Messrs. T. Oertling have a splendid collection of assay and chemical balances and accessories.

The central bench contains some interesting examples of modern electrical instruments made by the Cambridge

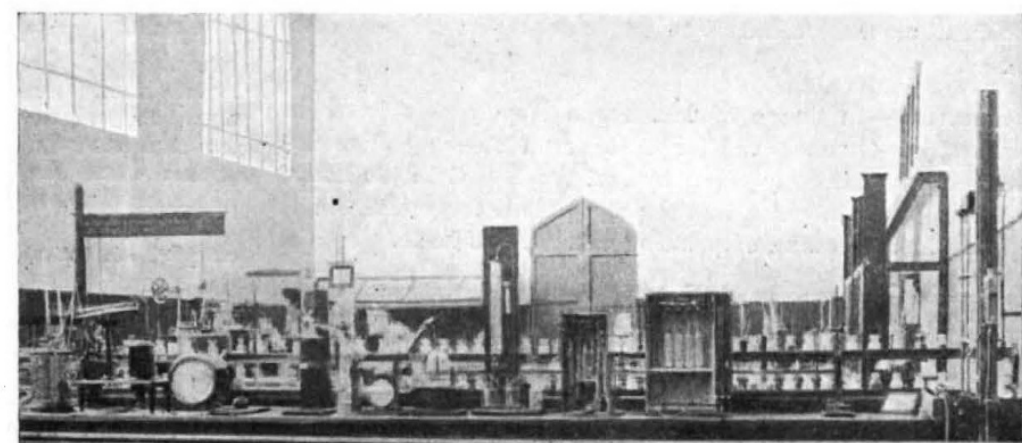

$$
\text { No. } 2 \text { I9O, VOL. 87] }
$$

FIG, r,-General View of Chemical Laboratory,

Scientific Instrument Company, amongst which are the "Duddell" oscillograph, with camera outfit, for use on circuits up to 50,000 volts, shown in operation; a "Callendar" recorder connected to an open-wound thermometer, by means of which a continuous record of the laboratory air temperature is obtained; the "Thread" recorder, connected to a copper couple, arranged so that its extreme sensibility can be shown; a laboratory type pyrometer with a platinum platinumiridium couple (this is used for showing the temperature of an electrically heated laboratory furnace).

Most of the firms showing in the laboratory also have good exhibits in the Physical Instruments Court.

On entering the chemical laboratory, the first bench on the left-hand side is a furnace bench of Yorkshire stone with a uralite hood. On this bench various furnaces by Messrs. Fletcher Russell and Co., Ltd., are exhibited, such as are employed in metallurgical and assay work; also laboratory burners of various design.

On the opposite side is a bench which is in part fitted up for electrochemical analysis, and here actual analytical operations are from time to time carried out by the laboratory demonstrator. On another part of the same bench 
the method of assaying gold in order to test its fineness is illustrated in a series of twelve operations by Messrs. Johnson and Matthey, who have also supplied the platinum electrodes for analysis. First a gold link taken from a watch chain is shown, (2) the hammered gold, (3) the rolled gold, (4) a weighed quantity ready for assay, (5) the gold with a piece of silver wrapped in lead, (6) the same in a cupel, (7) the gold-silver alloy hammered and rolled after cupelation, (9) the rolled and coiled alloy in the parting flask, (10) the gold after parting with nitric acid, (I I) the gold annealed, (12) the assayist's report. The assay balance and muffle employed in such operations are also shown. In still another part of the same bench various crucibles and other apparatus used in assay work are shown by the Morgan Crucible Co.

At another bench Messrs. Townson and Mercer show a large assortment of apparatus employed in various operations. Thus there is a centrifuge operated by means of an electromotor which is shown in operation. There is also apparatus for the analysis of explosives, and general apparatus, such as the Lewis Thompson calorimeter, hotair ovens, vacuum drying apparatus, \&c. A portion of this bench, which is provided with water and electrical heating, is reserved for general demonstrations, such as operations of filtration, crystallisation, precipitation, and

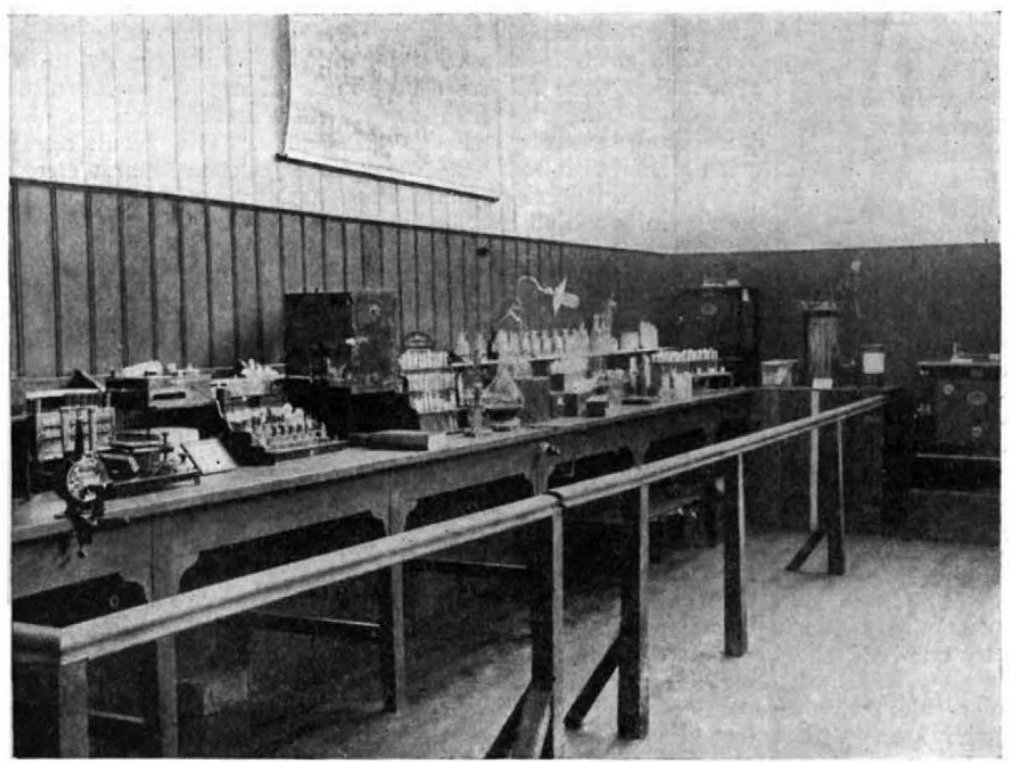

FIg. 2.-Bacteriolug ical Bench uhere cemonstrations were given. method.

as in Italy it was generally not known that silica apparatus was manufactured in England.

At the end of the laboratory a long bench is devoted to bacteriology, where Messrs. Baird and Tatiock make a display of the various apparatus used in bacteriological work, and also show cultures on solmedia, a powdered form of bacteriological culture. At another portion of the demonstration bench Messrs. Edward Cook and Co., the well-known soap-makers, have a demonstrator who shows the methods employed in the standardisation of disinfectants by the Rideal-Walker method and by the Lancet

On the next bench there is a working laboratory apparatus exhibited by Ozonair, Ltd., showing the formation of ozone. On another part of the bench there is a most interesting exhibit of old chemical apparatus used in the eighteenth century, kindly lent by the Society of Apothecaries, London.

In the centre of one side of the room Messrs. Burroughs, Wellcome and Co. have an exhibit showing the results obtained by the firm in research work, and in the manufacture of substances of pharmacological importance. Thus the formation of ernutin from ergot is graphically displayed. Investigations in the. Wellcome Physiological Research Laboratories have shown that ergot contains at least three active principles, and the exhibit is intended to show the production of these. This exhibit is of great interest, and demonstrates the high value of chemical research in technical operations.

There is also a lead-covered distillation bench, on which are shown the processes of distillation, fractionation, and extraction in operation.

This part of the British exhibit has attracted great attention, and the Board of Trade has been highly commended by other nations upon the new departure. At the same time, it must be mentioned that the whole of the British Section is most creditable to the Exhibitions Branch of the Board of Trade, without which it would not have been possible. Thus there is a splendid exhibit of textiles, and the exhibit of British motor-cars has attracted a large amount of interest. There is also a good exhibit of agricultural machinery and implements.

Most excellent catalogues have been drawn up to explain the various exhibits. The catalogue for the Mathematical and Scientific Instrument Section is in French and is splendidly illustrated. The apparatus is

so on. Demonstrations in dyeing are also given here, and the action of dyes on mordanted and unmordanted cotton, silk, \&c., illustrated. The apparatus for dyeing and material for these experiments are supplied by Messrs. Read Holliday, of Huddersfield.

Following this bench is a draught cupboard, which contains apparatus for the generation of sulphuretted hydrogen, carbon dioxide, and so on.

On the next bench the various apparatus employed in the analysis and examination of mineral oils is exhibited; for example, the method of estimating the viscosity by means of the viscometer is shown in operation, and also the taking of flash-points. Most of this apparatus is exhibited by Messrs. Baird and Tatlock, but the MahlerCook bomb calorimeter is shown by Messrs. J. J. Griffin and Sons, Ltd. There is also on the shelves a fine display of reagents and pharmaceutical products exhibited by Messrs. T. Morson and Son. On the opposite side of the bench the various apparatus employed in gas analysis is shown. There is also a good display of silica apparatus by the Silica Syndicate and the Thermal Syndicate. This apparatus has attracted a very great amount of attention, NO. 2 I9O, VOL. 877 most carefully and fully described both from the theoretical and practical aspect, and Mr. E. H. Rayner, who edited the catalogue, is to be congratulated upon its excellence.

The Catalogue of Chemical Industries, of which there is an English and French edition, commences with articles descriptive of the following industries, which have been written or revised by the persons whose names accompany the articles:-The alkali industry, J. F. L. Brunner and J. I. Watts; sulphuric acid and nitric acid, Dr. F. Mollwo Perkin; the gas industry and coal-tar products, Prof. Vivian Lewes ; cyanides and prussiates, A. Gordon Salamon and Dr. G. T. Beilby; electricity, Dr. G. T. Beilby; explosives, Walter F. Reid; nickel, J. F. L. Brunner; oils, fats and waxes, soaps and candles, Dr. J. Lewowitsch; petroleum and shale oil, Sir Boverton Redwood, Bart.; pharmacy, Thomas Tyrer and N. H. Martin; salt, J. F. L. Brunner and J. I. Watts; disinfectants and antiseptics, Dr. D. Somerville; rare metals, Dr. F. Mollwo Perkin. The catalogue is thus a small treatise on technical chemistry. The seccond part of the catalogue deals with the actual exhibits. 